\title{
Forecast of the regional EC development through an ANN model with a feedback controller
}

\author{
G. Jianquan ${ }^{1,3}$ Fankun $^{2}$, T. Bingyong ${ }^{1}$, B. Shi ${ }^{3}$ \& Y. Jianzheng ${ }^{3}$ \\ ${ }^{1}$ Donghua University, Shanghai, People's Republic of China \\ ${ }^{2}$ Shanghai Maritime University, Shanghai, People's Republic of China \\ ${ }^{3}$ University of Shanghai Science and Technology, \\ People's Republic of China
}

\begin{abstract}
This paper is to have a deep understanding of the way to forecast the economic development with the help of an Artificial Neural Network (ANN), putting forward a brand-new ANN forecast model, that is, the Back Propagation Networking Learning Algorithm (BP Networking Algorithm) with a feedback controller. The model has been used to overcome the deficiencies of the traditional BP Algorithm, as it is more accurate for forecasting, less dependable on initial data, and easier to select the needed number of hidden layers and hidden-layer neurons. In order to measure regional electronic commerce development we have set an evaluation system, which seems to be comparatively perfect and manipulative. With the model and the system, we carried out a regional EC forecast in Huai'nan, a medium-sized city in Anhui Province, China. The result of the case study has indicated that the model has an ideal extension, the number of its hidden-layer neurons can easily be decided, and we are to have a long-term forecast of the development without much initial data. With this model in hand, it is possible to cope with the problems of sparse, dispersed and hard-to-forecast statistical information in the development of electronic commerce.
\end{abstract}

Keywords: feedback controller, BP model, EC development, forecast. 


\section{Introduction}

There has appeared all over the world a new business model-electronic commerce with the rapid development and application of information technology and communication technology represented by Internet and mobile technology. And based on this, a brand new economic formation has come into being-the Internet economy. As far as the nature of the Internet economy is concerned, it is global, but we may easily find that it has some regional characteristics in its development [1]. If we put it in the scale of the globe, it appears to be "North American" [2]. If we narrow our insight to the Mainland China, we also have the same phenomenon in this field. There is much faster EC development in the Yangtzi River Delta than those in the inner part of the mainland. Therefore, some economists advocate "the Ribbon Development Strategy"-focusing our attention of the development of the electronic commerce along the coastal regions, and "the Centralized Development Strategy" [3]_-initiating the development of the E-business in Beijing, Shanghai, and Guangdong Province where there are adequate web users.

It is of great importance to have a study of the different level of the EC development in different regions. First of all, EC stands for the new economy or the Internet economy. The EC development represents to a great extent the development of the Internet economy.

Secondly, the world seems to run out of natural resources, and there are more and more countries and regions showing solicitudes for this. The Internet economy has become a platform for the growth in many economies as it has its inherent attributes of low energy costing, and many economic entities have been pursuing a sustainable development with as little consumption of natural resources as possible.

Thirdly, with the help of electronic commerce - a new business model, some less developed economies have got a short cut to catch up with the development of other countries and to have a close connection with the rest of the world. Anyway, national and regional competitiveness in the age of the Internet will require "being in the loop" more than ever before [4].

John C. Scott put forward a model called Internet Maturity in 2000, which highlighted the 4 stages of the development of the Electronic Commerce in businesses. It also explained thoroughly the way businesses stepped onto the highly developed stage of EC with such techniques as integrated skills and reengineering. This model was developed in somewhat the same way as the three stages of EC development presented by Yang Jianzheng in his Principles and Applications of the Electronic Commerce and the Tri-level Model of EC development and the Bi-level Model of EC development in 2003 China Ebusiness Almanac. Unfortunately, these theories or models do not touch upon the study of the EC development in different regions.

It is considered difficult to implement the study of EC development in different regions because of the three handicaps: the construction or selection of models, the construction of measurement systems, and the collection of initial 
data for statistics. This paper is to deploy studies in these three spheres respectively.

\section{Construction of the model}

The recently developed ANN Model is an active branch in artificial intelligence. ANN is a newly developed information processing system on the bases of the study of modern neurology, which simulates the biologic nerve system and seems to be able to process an array of information simultaneously. It can be used to process information by association, generalization, analogy, and reasoning. It has an advantage of self-learning, the capability of distilling features, summing up knowledge, and forecasting futures on the gained experiences. It is also full of adaptability, systematization, and an ability of learning, associating, infrastructure problem solving, and noise eliminating [5]. Therefore, ANN has its bright future in the economic forecast. A few Chinese specialists have set foot in this field. But if we use the traditional BP ANN model, it will be very difficult to ascertain the number of its hidden-layer neurons or the units in each layer, and will prolong the time for study [5]. On the bases of study of the economic forecast with ANN, we try to put forward a new ANN forecast model - the BP Model with Feedback Controller. Ours, we think, is more accurate, easier for the selection of the number of hidden-layer neuron and the units in each layer with fewer initial data needed. It has overcome the shortcomings of the traditional BP Models and become more applicable.

\subsection{ANN with feedback controller}

Our model is an amelioration of the Error Back Propagation Network. The BP Model is a multi-layer feed forward artificial neural network, which is composed of input layers, hidden layers, and output layers, and each layer has one or more neurons (Figures 1 and 2). There is no connection in the same layer, but there exists among the neighbouring layers.

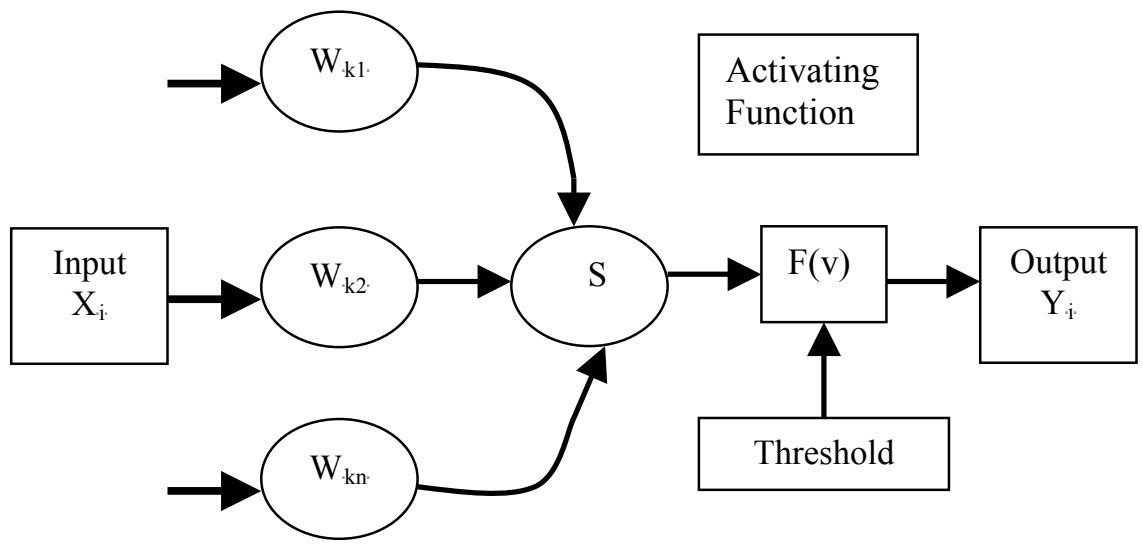

Figure 1: Neuron. 


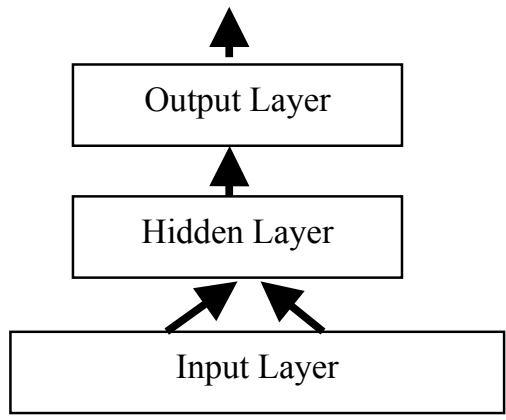

Figure 2: Neural network constructions.

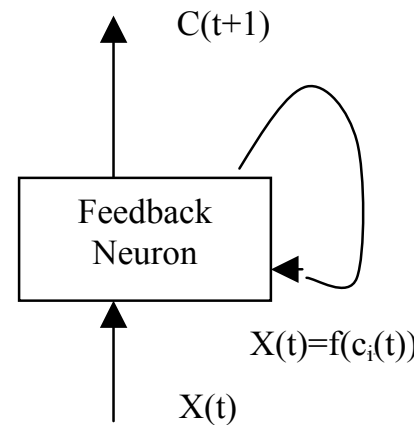

Figure 3: Feedback neuron. Figure 4: Feedback neural network

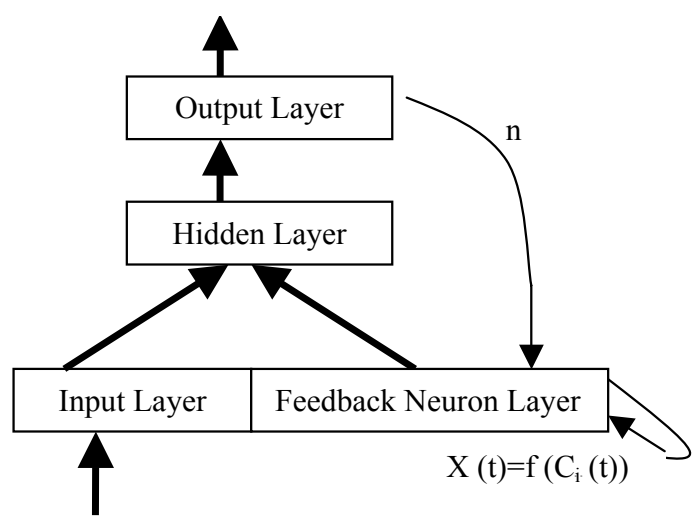
structure.

But the ordinary BP Networks could only achieve an ideal result of forecast with adequate samples and enough time for measurement when forecasting economic development. Practically, however, we always need to do some forecast on condition that there is not very much statistics. This is the reason why we try to improve the BP Networks with a feedback controller added. (Figures 3 and 4).

There could be one or more units for feedbacks accordingly to different questions. There may exist various kinds of feedback controlling functions, but usually simple function is enough to solve the ordinary problems. Our renovated neural network has developed from a static state to a dynamic one. Especially when $\mathrm{f}(\mathrm{x})=\mathrm{x}$, it will degenerate into a BP Network with some co-connected neurons. The net-learning arithmetic usually adopts Error Back Propagation Algorithm. 


\subsection{Network-learning algorithm}

BP (Error Back Propagation) is a multi-layer artificial neural network, comprising input, hidden and output layers. There is full inter-layer connection but no intra-layer connection of neurons. Figure 5 demonstrates a three-layer BP neural network with nine neurons.

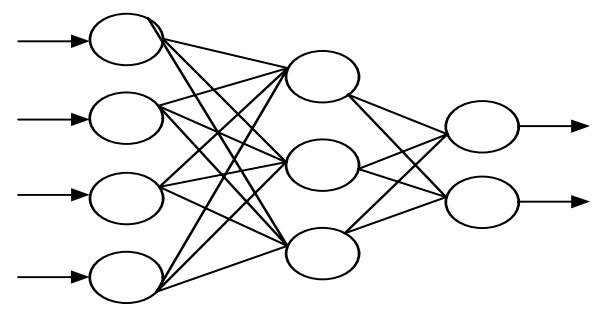

Figure 4: A three-layer BP neural network.

\subsubsection{Rationale of BP network}

Suppose the input mode vector $A_{k}=\left(a_{1}, a_{2}, a_{3}, \ldots a_{n}\right), k=1,2,3 \ldots m$. Here, $m$ is the number of learning modes; $n$ is the number of neurons in the input layer. Correspondingly, the expected output vector $\mathrm{Y}_{\mathrm{k}}=\left(\mathrm{y}_{1}, \mathrm{y}_{2}, \mathrm{y}_{3}, \ldots, \mathrm{y}_{\mathrm{q}}\right)$, and $\mathrm{q}$ is the number of the output neurons.

The calculation process of the input of the neuron in each hidden layer is follows:

$$
s_{j}=\sum_{i=1}^{n} w_{i j} a_{i}-\theta_{j}, j=1,2, \ldots, p
$$

In this formula, $w_{i j}$ is the connection weight ranging from the input layers to hidden layers; $\theta_{j}$ is the threshold value of neuron in the hidden layer; $\mathrm{p}$ is the number of the neurons in the hidden layer.

To simulate the non-linear features of the biologic neurons, make $s_{j}$ the independent variable of the sigmoid function, so as to calculate the output of each neuron in the hidden layer. The Sigmoid function is as follows:

$$
f(x)=1 /\left(1+e^{-x / x_{0}}\right)
$$

Here $f(x)$ is activation function, and the activation value of the neurons in the hidden layer is:

$$
b_{j}=f\left(s_{j}\right) \quad j=1,2, \ldots, p
$$

While information is flowing from the input layer to the output layer, if we provide the input information, we can get an output as follows:

$$
\begin{array}{r}
L_{t}=\sum_{j=1}^{n} v_{j t} b_{j}-\gamma_{t} \\
c_{t}=f\left(L_{t}\right), t=1,2, \ldots, q
\end{array}
$$


It has been theoretically proved that there exists a three-layer network that can achieve the mapping action of any consecutive function with whatever accuracy required [6].

To carry out the mapping action, the network needs to be trained through the following steps:

1. Initialization of the weight value and threshold value. Choose at random an initialized weight value and threshold value from the interval $(0,1)$;

2. Set input vector $A$ and output vector $Y$;

3. Calculate the actual output vector $C$;

4. Revise the weight value, starting from the output layer, propagate the error signal backward, and try to minimize the error by revising different weight values;

5. Adopt $\mathrm{Y}_{k}=\left(y_{1}^{k}, y_{2}^{k}, \ldots, y_{n}^{k}\right)$, the desirable output mode, and $\left\{\mathrm{C}_{\mathrm{t}}\right\}$, the actual network output, to calculate $\left\{d_{j}^{k}\right\}$, the error of different neurons in the hidden layer; its formula is as follows:

$$
d_{j}^{k}=\left(y_{t}^{k}-c_{t}\right) \cdot c_{t}\left(1-c_{t}\right), t=1,2, \ldots, q
$$

6. Use $\left\{v_{\mathrm{jt}}\right\}$, the connection weight, $\left\{\mathrm{d}_{\mathrm{t}}\right\}$, the error, and $\left\{b_{\mathrm{j}}\right\}$, output of the hidden layer, to calculate the error of different neurons in hidden layers, namely $\left\{e_{j}^{k}\right\}$.

$$
e_{j}^{k}=\left(\sum_{i=1}^{q} d_{t} \cdot v_{j t}\right) \cdot b_{j}\left(1-b_{j}\right), j=1,2, \ldots, p
$$

7. To revise $v_{j t}$, the connection weight, and $\gamma_{t}$, the threshold value by using $\left\{d_{j}^{k}\right\}$, the error of different neurons in the output layer and $\left\{b_{\mathrm{j}}\right\}$, the output of different neurons in the hidden layers:

$$
\begin{gathered}
v_{j t}(N+1)=v_{j t}(N)+\alpha \cdot d_{t}^{k} \cdot b_{j}, j=1,2, \ldots, \mathrm{p} ; \mathrm{t}=1,2, \ldots, \mathrm{q} \\
\gamma_{t}(N+1)=\gamma_{t}(N)+\alpha \cdot d_{t},(0<\alpha<1)
\end{gathered}
$$

8. To revise $\left\{w_{i j}\right\}$, the connection weight, and $\left\{\theta_{j}\right\}$, the threshold value, by using $\left\{e_{j}^{k}\right\}$, the error of different neurons in the hidden layers and $\mathrm{A}_{\mathrm{k}}$, the input of different neurons in the input layers.

$$
\begin{gathered}
w_{i j}(N+1)=w_{i j}(N)+\beta \cdot e_{j}^{k} \cdot d_{i}^{k}, i=1,2, \ldots, \mathrm{n} ; j=1,2, \ldots, \mathrm{p} \\
\theta_{j}(N+1)=\theta_{j}(N)+\beta \cdot e_{j}^{k}, j=1,2, \ldots, \mathrm{p}
\end{gathered}
$$

9. Choose the next learning mode for the network, return to step 3, until all (m) modes are finished with the training.

10. Once again, choose at random a mode from $\mathrm{m}$, return to step 3 , if global error $\mathrm{E}$ is smaller than a preset small value, then the neural network is 
convergent. Or else, if learning time is bigger than a preset value, which means the network cannot converge any more. The formula is as follows:

$$
E=\sum_{k=1}^{m} \sum_{t=1}^{q}\left(y_{t}^{k}-c_{t}\right)^{2} / 2
$$

$\mathrm{BP}$ algorithm is actually a kind of gradient algorithm, namely:

$$
w(\mathrm{t}+1)=\mathrm{w}(\mathrm{t})+\left.\eta\left(-\frac{\partial E}{\partial \mathrm{w}}\right)\right|_{w=w(t)}
$$

\section{Construction of index system}

The level of regional EC development can be used to reflect the integrated situation of the development of Electronic Commerce in that region. Therefore, it is necessary to select all the indexes from various spheres for the assessment.

With the consideration of the function of different sub-systems and the logical relationship between different levels of sub-systems, this paper will, in measuring the development level of the regional E-business Y, break the measurement system down into four first-grade sub-systems, which are: trading capability $\mathrm{X}_{1}$, supporting trading capability $\mathrm{X}_{2}$, development potential $\mathrm{X}_{3}$ and governmental support $\mathrm{X}_{4}$. Each first-grade sub-system is composed of several minor indexes. The particular index system is shown in the following table 1 .

\section{Case studies}

\subsection{Background information and initial data}

This study is based on the practice in Huai'nan, Anhui Province. As a major city for coal and power generation, the medium-sized city has many big energy enterprises spread in several districts. Those businesses are generally advanced in information processing and hoist the EC development in the city. In order to promote the electronic commerce, the city started in 2004 a project called Digital Huai'nan. The project will be unfolded in all the 7 districts of the city, that is, tianjia'an, Panji, Maoji, Bagongshan, Xiejiaji, Datong and Fengtai.

\subsection{Analysis of the model construction and calculation}

This paper is to forecast the development of the EC transactions in the districts in Huai'nan with BP Model. The analysis has its foundation of assessments, and the logic of the assessment of the EC development is as follows:

The index $X_{1}$ is achieved by calculation of the 4 items: $X_{11}, X_{12}, X_{13}$ and $X_{14} . X_{2}$ is achieved by calculation of the 3 items: $X_{21}, X_{22}$, and $X_{23}$. Of the 3 indexes $X_{21}, X_{22}$, and $X_{23}, X_{21}$ is calculated through the following 5 items: $X_{211}$, $\mathrm{X}_{212}, \mathrm{X}_{213}, \mathrm{X}_{214}$, and $\mathrm{X}_{215} . \mathrm{X}_{22}$ is calculated through the 3 items: $\mathrm{X}_{221}, \mathrm{X}_{222}$, and $X_{223} . X_{23}$ is calculated through the 4 items: $X_{231}, X_{232}, X_{233}$, and $X_{234} . X 3$ is calculated through the 5 items: $X_{31}, X_{32}, X_{33}, X_{34}$ and $X_{35}$. $X 4$ is calculated 
through the following 3 items: $\mathrm{X}_{41}, \mathrm{X}_{42}$, and $\mathrm{X}_{43}$. The index $\mathrm{Y}$ is calculated through $\mathrm{X}_{1}, \mathrm{X}_{2}, \mathrm{X}_{3}$, and $\mathrm{X}_{4}$.

Table 1: $\quad$ The index system.

\begin{tabular}{|c|c|c|c|}
\hline \multirow{21}{*}{$\begin{array}{l}\text { Overall } \\
\text { capability } \\
\text { Y }\end{array}$} & \multirow{4}{*}{$\begin{array}{l}\text { Trading } \\
\text { capability } \\
\mathrm{X}_{1}\end{array}$} & \multicolumn{2}{|c|}{ The percentage of e-business turnover in GDP $\mathrm{X}_{11}$. } \\
\hline & & \multicolumn{2}{|c|}{ The percentage of e-business dealers $\mathrm{X}_{12}$} \\
\hline & & \multicolumn{2}{|c|}{ The extent to which the dealing cost has been reduced $\mathrm{X}_{13}$} \\
\hline & & \multicolumn{2}{|c|}{$\begin{array}{l}\text { The extent to which the dealing time has been reduced } \\
X_{14}\end{array}$} \\
\hline & \multirow{9}{*}{$\begin{array}{l}\text { Supporting } \\
\text { trading } \\
\text { capability } \\
\mathrm{X}_{2}\end{array}$} & \multirow[b]{2}{*}{$\begin{array}{l}\text { Supporting } \\
\text { trading } \\
\text { capability } \\
\text { of infrastructure } \\
\mathrm{X}_{21} \text {. }\end{array}$} & Degree of popularity of computer $\mathrm{X}_{211}$ \\
\hline & & & \begin{tabular}{|l|} 
Degree of popularity among net-user \\
$\mathrm{X}_{212}$ \\
The percentage of enterprises net-users \\
$\mathrm{X}_{213}$ \\
Credit card per head $\mathrm{X}_{214}$ \\
$\begin{array}{l}\text { The proportion of investment on e- } \\
\text { business in total investment } \mathrm{X}_{215}\end{array}$ \\
\end{tabular} \\
\hline & & \multirow{3}{*}{$\begin{array}{l}\text { Supporting } \\
\text { trading } \\
\text { capability of } \\
\text { labor resource } \\
\mathrm{X}_{22} \text {. }\end{array}$} & $\begin{array}{l}\text { The proportion of e-business personnel in } \\
\text { the overall employed } \mathrm{X}_{221} \text {. }\end{array}$ \\
\hline & & & $\begin{array}{l}\text { The proportion of e-business personnel } \\
\text { with bachelor degree or above in the } \\
\text { overall employed } \mathrm{X}_{222}\end{array}$ \\
\hline & & & $\begin{array}{l}\text { The proportion of e-business teaching } \\
\text { program participators in the overall } \\
\text { teaching program participators } \mathrm{X}_{223} \text {. }\end{array}$ \\
\hline & & \multirow{4}{*}{$\begin{array}{l}\text { Supporting } \\
\text { trading } \\
\text { capability of } \\
\text { management } \\
\text { and safety } \mathrm{X}_{23} \text {. }\end{array}$} & $\begin{array}{l}\text { Available or unavailable of e-business } \\
\text { safety center } X_{231} \text {. }\end{array}$ \\
\hline & & & $\begin{array}{l}\text { The proportion of installation of anti- } \\
\text { virus software in computers } \mathrm{X}_{232}\end{array}$ \\
\hline & & & $\begin{array}{l}\text { The proportion of updating anti-virus } \\
\text { software in computers } X_{233}\end{array}$ \\
\hline & & & $\begin{array}{l}\text { The proportion of virus-related damages } \\
\text { in the overall business turnover } \mathrm{X}_{234}\end{array}$ \\
\hline & \multirow{5}{*}{$\begin{array}{l}\text { Potential of } \\
\text { development } \\
\mathrm{X}_{3} \text {. }\end{array}$} & \multicolumn{2}{|c|}{ The average ADR of net shares $\mathrm{X}_{31}$} \\
\hline & & \multicolumn{2}{|c|}{ The average price-to-earnings ratio of net shares $X_{32}$} \\
\hline & & \multicolumn{2}{|c|}{ Degree of popularity among net-user $X_{33}$} \\
\hline & & \multicolumn{2}{|c|}{ The percentage of enterprises net-users $\mathrm{X}_{34}$} \\
\hline & & \multicolumn{2}{|c|}{ The market accessibility of e-business $X_{35}$. } \\
\hline & \multirow{3}{*}{$\begin{array}{l}\text { Government } \\
\text { support } \\
\mathrm{X}_{4}\end{array}$} & \multicolumn{2}{|c|}{ The availability of special fund to support e-business $\mathrm{X}_{41}$. } \\
\hline & & \multicolumn{2}{|c|}{$\begin{array}{l}\text { The availability of special project arrangements to support } \\
\text { e-business } X_{42} \text {. }\end{array}$} \\
\hline & & \multicolumn{2}{|c|}{$\begin{array}{l}\text { The availability of government measures to support } \\
\text { e-business } \mathrm{X}_{43} \text {. }\end{array}$} \\
\hline
\end{tabular}


We calculate the level of EC development as follows:

The 3-layer BP Model is used for the calculation. We set different numbers of the input and output neurons according to the different requirements for indexes. At the same time, some adjustment was also made to the number of the hidden-layer neurons. For example, $\mathrm{X}_{1}$, the capability of EC transactions, adopts 4 input neurons $\left(\mathrm{X}_{11}, \mathrm{X}_{12}, \mathrm{X}_{13}\right.$ and $\left.\mathrm{X}_{14}\right)$ and one output neuron $\left(\mathrm{X}_{1}\right)$, while 8 neurons were chosen for the number of neurons in hidden-layer. All the other indexes were processed more or less the same way as $\mathrm{X}_{1}$.

By these ways the overall capability $\mathrm{Y}$ of each district is calculated.

\subsection{Result of the calculations}

\subsubsection{The calculation for the forecast of EC development}

The calculation is accomplished with the 3-layer BP model. Because the problem comes across as a non-linear time series problem, it is not proper to use an ordinary BP neuron network. Therefore, we use a BP neuron network with some controlling functions. Among which, there is one input neuron, one output neuron, and 10 neurons in the hidden-layer. Based on the initial data, we tried to forecast the 2005 EC development in various districts of Huai'nan. Listed below is only the result of the forecast of EC development in Tianjia'an District. (Table 2 and Figure 6.)

Table 2: $\quad$ The forecast of EC development in Tianjia'an District.

\begin{tabular}{|c|c|}
\hline Year & Tianjia'an District \\
\hline 2005 & 0.686299 \\
\hline 2004 & 0.5815752 \\
\hline 2003 & 0.4895732 \\
\hline 2002 & 0.4097342 \\
\hline 2001 & 0.3412378 \\
\hline 2000 & 0.2830835 \\
\hline 1999 & 0.23417 \\
\hline
\end{tabular}

\subsubsection{Analysis of the forecast of the EC development}

We have got several unique characteristics from the result of forecast. First, there have been evident developments of the EC transactions in all the districts, which is relevant to the domestic and international economic environment. Second, as far as the EC development in the past few years is concerned, Tiania'an, Fengtai, and Xiejiaji Districts are the first three in transaction amounts and the growth rate. This reflects the global reality that in the launching stage of the EC development, the regions, which have solid economic foundations usually, take the lead. Third, we are once again assured from the assessment that the major driver of the EC development, that is, the government support, plays a very important role in this field. The draft of the EC development from 2002 to 2003 in various regions shows us that China Electronic Administration Year promoted greatly the EC development in these areas. Fourth, B2B transactions are the main force in the EC development in all the districts. 


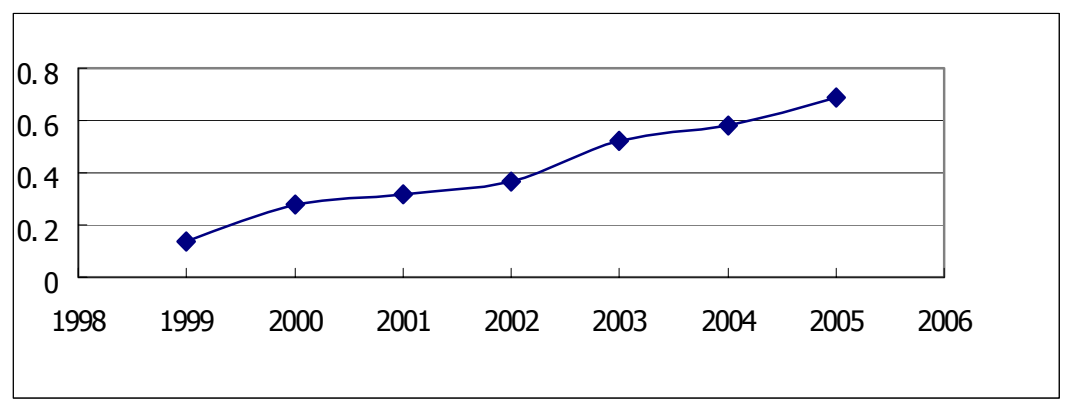

Figure 6: The forecast of EC development in Tianjia'an District

\section{Conclusion}

This paper has introduced a new scientific means to assess and forecast the EC development in a region. The ANN with a feedback controller adopted in our study has solved the problem of sparse, dispersed and hard-to-forecast statistical information in the development of the electronic commerce. We have constructed a model for assessment and forecast, and implement some calculation with initial data from a sample region. The ANN is a data-oriented method of analysis. We took the model of this kind because the regional EC development is new area for study, and we have not had much systematic arithmetic analysis. One the other hand, the problem we have is systematically sophisticated, non-linear, multi-indexed, and non-adequate, so we are not able to deal with it with the traditional arithmetic models. The ANN is also full of the abilities of self-learning, self-organizing, self-adapting, and problem solving, and is a proper choice for the study of new and sophisticated systems.

\section{References}

[1] Guojianquan, Analysis of Network Economy. Journal of East China Normal University. No.1, pp.56-61, 2004.

[2] Joanne E Oxley, Bernard Yeung, E-commerce Readiness: Institutional environment and international competitiveness. Journal of International Business Studies, (4), pp.705-706, 2001.

[3] Yang Jianzheng, Principles and Applications of the Electronic Commerce. Publication of University of Xi'an Electronic and Technology: Xi'an pp. 144 145, 2001.

[4] Edward E. Leamer, Michael Stroper, The Economic Geography of the Internet Age. Journal of International Business Studies, (4), pp. 660 661, 2001 .

[5] Jiao Licheng, Algorithm of Neural Network, Publication of University of Xi'an Electronic and Technology, Xi'an, pp. 249-294, 1995.

[6] Jiao Licheng, System Theory of Neural Network. Publication of University of Xi'an Electronic and Technology, Xi'an, 1995. 